\title{
Pt/Co ディスクの繰り返し書き換え特性
}

\author{
Write/Erase Cyclability of Pt/Co Magneto-Optical Disks \\ 中村純子・粟野博之・宮本治一・高橋正彦・尾島正啓 \\ (株)日立製作所中央研究所, 国分寺市東恋ヶ窪 1-280 (更185) \\ J. Nakamura, H. Awano, H. Miyamoto, M. Takahashi and M. Ojima \\ Central Research Laboratory, Hitachi, Ltd., 1-280 Higashikoigakubo, Kokubunji 185
}

Write/erase cyclability on Co-rich Pt/Co disks was studied, along with its limiting factors. Annealing experiments suggested that a decrease in CNR resulted from degradation of the perpendicular mag. netic anisotropy in a Pt/Co film heated by an erasing laser beam. The main mechanism of the degradation is atomic intermixing at the interface in $\mathrm{Pt} / \mathrm{Co}$ multilayers. In the case of a Pt/Co film exposed to air, Co might be oxidized during the erasing cycles. The higher peak temperature of $\mathrm{Pt} / \mathrm{Co}$ films accelerates the intermixing. Therefore, the number of cycles was increased by adding a heat-diffusive layer to the $\mathrm{Pt} / \mathrm{Co}$ film in order to decrease the peak temperature. For example, Au-coated Pt/Co disks were capable of $10^{5}$ cycles, on account to the lower peak temperature $\left(430^{\circ} \mathrm{C}\right)$, whereas SiN-coated Pt/Co disks, whose peak temperature was $770^{\circ} \mathrm{C}$, were capable of only $10^{2}$ cycles.

Key words: ' write/erase cyclability, magneto-optical disk, Pt/Co multilayered film, peak temperature, perpendicular magnetic anisotropy, atomic intermixing, heat-diffusive layer

\section{1.はじめに}

$\mathrm{Pt} / \mathrm{Co}$ 多層膜は, 波長 $500 \mathrm{~nm}$ 以下の短波長光領域で のカー回転角 $\theta_{\mathrm{K}}$ が大きい" ことから, 緑色あるいは青色 の短波長レーザを用いた高密度光磁気記録用媒体として 注目されている。これまでの研究では主に保磁力や垂值 磁気異方性エネルギー $\left(K_{y}\right)$ の向上に重点が置かれてき た. その結果，スパッタガスに Xe など原子量の大きな ガスを用いる，あるいは，下地膜をエッチング処理する ことにより $K_{\mathbf{u}}$ が増大することが明らかになってい

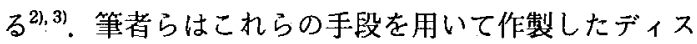
クにおいて，ノイズが低い良好な $\mathrm{C} / \mathrm{N}$ が得られること を確認した ${ }^{4) 5}$. 一方, Pt/Co ディスクの繰り返し書き換 え特性についての報告は少ない. 1991 年 Carcia らは, Pt-rich の Pt/Co ディスクの書き換え回数は $10^{4}$ 回以上 であるが, Co-rich の 膜では $10^{2} \sim 10^{3}$ 回となることを
報告している6)，この結果は $\mathrm{Pt} / \mathrm{Co}$ 膜を用いて高密度記 録を行う上で重要な問題点を提示している. すなわち, 高密度に記録した微小磁区を高 $\mathrm{S} / \mathrm{N}$ で再生するには, カー回転角の大きな Co-rich 膜を用いる必要があるが, 書き換え回数の点で実用化が困難となるからである。

そこで, 本研究では, Co-rich の Pt/Co 膜を記録膜と したディスクの書き換え特性向上を目的として，書き換 え時の光照射により Pt/Co 膜が受ける熱的影響と書き 換え回数との関係を調べた，さらに書き換え少化メカ二 ズムについて考察した。

\section{2. 実験方法}

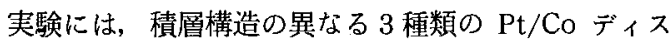
クを用いた. Fig. 1 に各ディスクの断面構造を示す. ディスク A は, SiN 下地膜上に Pt/Co 膜を積層した 2

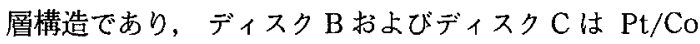
膜上にさらに保護膜として $\operatorname{SiN}$ 膜および $\mathrm{Au}$ 膜をそれ ぞれ設けた 3 層構造である. 保護膜の厚さは $100 \AA$ とし た.これらのディスクにおけるPt層とCo層の厚さ, $\mathrm{Pt} / \mathrm{Co}$ 膜の全膜厚, および作製条件は同じである.

記録膜はマグネトロンスパッタ法により作製した. $\mathrm{UV}$ 樹脂で $1.4 \mu \mathrm{m}$ ピッチの案内溝を設けたガラス基板 上に，反応性 RF スパッタリングにより $\operatorname{SiN}$ 膜を形成 し，この表面にスパッタエッチングを施した，このエッ チング処理を行うこよにより， SiN 膜表面の凹凸が 50

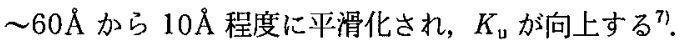
三つの $\mathrm{Pt} / \mathrm{Co}$ ディスクに拉けるエッチング処理後の

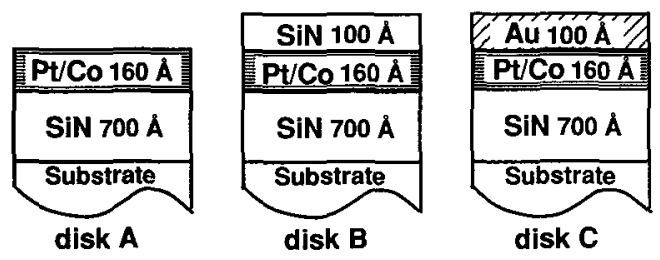

Fig. 1 Disk structures. 


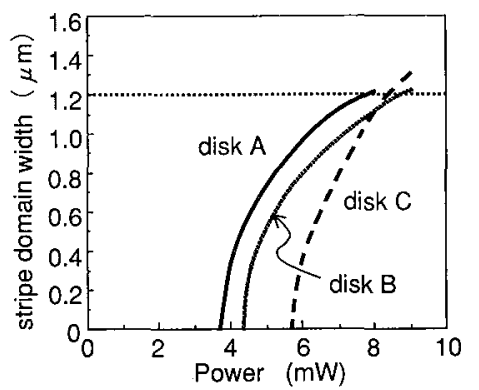

Fig. 2 Writing power dependence of stripe domain width with a DC laser beam.

$\mathrm{SiN}$ 膜の厚さはいずれも $700 \AA$ である. $\mathrm{Pt} / \mathrm{Co}$ 多層膜は 8 mTorr の Xe ガスを用いて, Pt t RF スパッ夕, Co を DC スパッタにて作製した。膜構造は Co 層膜厚 2.6 $\AA \mathrm{At}$ 層膜厚 $6.8 \AA$ であり, $\mathrm{Pt}$ から積層し $\mathrm{Pt}$ を最上首と した.このとき，第 1 層の $\mathrm{Pt}$ の膜厚は $30 \AA$ とした. Pt/ $\mathrm{Co}$ 全膜厚は，14 層分に Pt $30 \AA$ を足した約 $160 \AA$ であ る.この $\mathrm{Pt} / \mathrm{Co}$ 膜上に, ディスク B では $\mathrm{SiN}$ 膜を $\mathrm{Ar}$ / $\mathrm{N}_{2}$ 混合ガスにて製膜し，ディスクCでは Arガスによ り Au膜を製膜した。

カ一回転角及び保磁力はカーヒステリシス曲線から求 め, 磁化および $K_{\mathrm{u}}$ はそれぞれ試料振動型磁力計 (VSM), トルクメータを用いて測定した，また，膜構造 は X 線回折法 $\left(\mathrm{Cu}-K_{\alpha}\right)$, 膜中の酸素含有量は二次イオン 質量分析法 (SIMS) により調べた。

作製したディスクの記録再生特性には，波長 $830 \mathrm{~nm}$ の半導体レーザ，NA0.55 の絞り込みレンズを有する光 ヘッドを搭載した光磁気ディスクドライブを用いた。 線 速度は $8.9 \mathrm{~m} / \mathrm{s}$ とし，記録周波数 $1 \mathrm{MHz}$ ，記録時バイア 不磁界 $300 \mathrm{Oe}$ の条件で記録し， $1 \mathrm{~mW}$ のパワーで再生 した．この時の記録パワーは，2 次高調波レベルが最低 となるレーザパワーとした，書き換え特性の評価では， DC 光を多数回照射して繰り返し消去を行い，その後， 前述した条件で記録した時の $\mathrm{C} / \mathrm{N}$ を測定した，消去特 性を評価した結果, $\mathrm{DC}$ 光で消去される磁区幅と, 記録 されるストライプ状磁区の幅がほ等しかったことか ら，ここでは記録磁区幅から消去パワーを求めた，具体 的には，記録磁区を偏光顕微鏡観察により測長し，その ストライプ状磁区の幅が $1.2 \mu \mathrm{m}$ になるようにした。こ の値は，現在製品化されている $\mathrm{TbFeCo}$ ディスクの消 去幅に合わせたすのである.

\section{3. 実験結果と考察}

\section{1 書き換元特性}

Fig. 2 に各ディスクにおける DC 光パワーと記録され

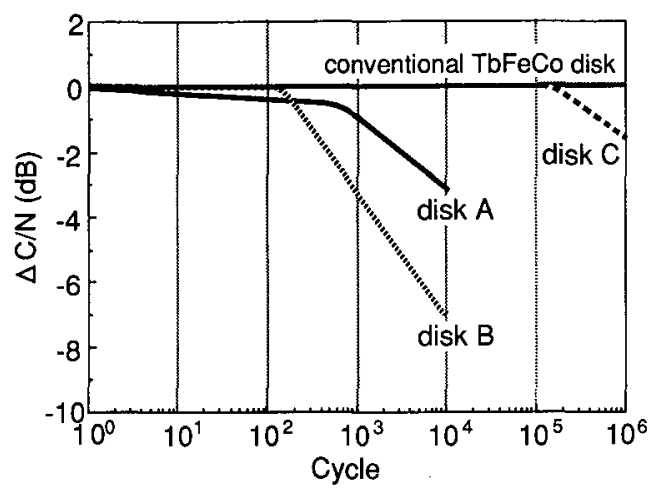

Fig. 3 Change in $\mathrm{C} / \mathrm{N}$ with write/erase cycles.

たストライプ状磁区幅との関係を示す。磁区が記録され 始めるパワーはディスク A，B，C の順に高くなってお り, $\mathrm{Pt} / \mathrm{Co}$ 膜と接している物質の熱伝導率の大小関係 （空気 $<\mathrm{SiN}<\mathrm{Au}$ ) と一致している.しかし， $1.2 \mu \mathrm{m}$ 幅 の磁区が記録されるパワー $\left(P_{\mathrm{E}}\right)$ は，ディスク $\mathrm{A}, \mathrm{B}, \mathrm{C} の$ 順にそれぞれ 7.5, 8.5, $8.2 \mathrm{~mW}$ となり，ディスク $\mathrm{B}$ と $\mathrm{C}$ の順番が逆転する。このことから, 熱伝導率が高い保護 膜の持つディスクほど，記録膜を記録可能温度に昇温さ せる高パワーが必要であるが，幅の広い磁区は記録しゃ すいことがわかった。この結果は，三つのディスクに扔 いて DC 光照射時における記録膜内の温度分布が異なる ことを示している.

Fig. 2 で得られた $P_{\mathrm{E}}$ を連続的に照射して繰り返し消 去を行い，各ディスクにおける書き換え特性を調べた． その結果を Fig. 3 に示す，初期の $\mathrm{C} / \mathrm{N}$ はいずれむ 58 〜 $59 \mathrm{~dB}$ と良好な值であり, 三つのディスクに大差はな い、しかしながら書き換え回数は異なり，ディスク Bて は約 $10^{2}$ 回から $\mathrm{C} / \mathrm{N}$ の劣化が起こるが，ディスク $\mathrm{C}$ は $10^{5}$ 回まで $\mathrm{C} / \mathrm{N}$ の変化は見られなかった。

本研究では $\mathrm{Pt} / \mathrm{Co}$ 膜の保護膜として Au を用いたこ とにより，105 回の書き換え回数を達成することができ た。ここで用いた Pt/Co 膜は Co-rich 膜であり, 高い キュリ一温度 $\left(T_{\mathrm{c}} ;\right.$ 約 $\left.380^{\circ} \mathrm{C}\right)$ を有している. Carcia ら は， $T_{\mathrm{c}}$ 之書き換え回数には密接な関係があり， $T_{\mathrm{c}}$ を低 くすることによって書き換え回数は向上すると報告して いる( ${ }^{6}$ が，本研究によって，高 $T_{\mathrm{c}}$ の $\mathrm{Pt} / \mathrm{Co}$ ディスクて む，ディスク構造を工夫することにより書き換え回数が 向上することがわかった。

$\mathrm{C} / \mathrm{N}$ の少化の最も激しかったディスク $\mathrm{B}$ ，書き換 え回数に対するキャリアレベルとノイズレベルの変化を Fig. 4 に示す。書き換えを多数回繰り返すと，まずノィ ズレベルが上昇し，その後キャリアレベルが低下する. ノイズレベルの上昇は, 主に未記録時のノイズ增大に起 日本応用磁気学会誌 Vol. 17, No. 5, 1993 


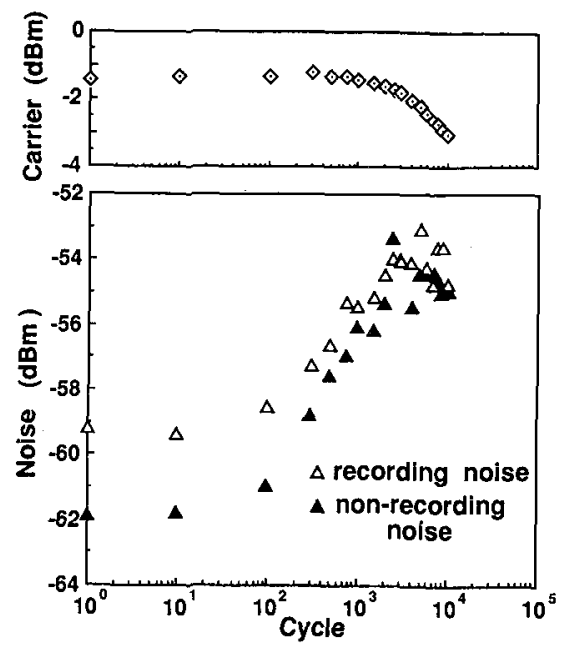

Fig. 4 Degradation of carrier and noise level with write/erase cycles for disk $B$.

因していることから，記録時に生じる磁区形状の乱机等 によるノイズが原因ではないと考えられる。そここで，初 期時の記録磁区之書き換え回数 $10^{3}$ 回後の記録磁区 (C) $\mathrm{N}$ 約 $4 \mathrm{~dB}$ 低下)，および $10^{4}$ 回後（約 $7 \mathrm{~dB}$ 低下）の記 録磁区を偏光顕微鏡により観察し， C/N 低下の原因を 調べた. Fig. 5 に示すように, 書き換え回数 $10^{3}$ 回後で は，記録磁区の中心に初期時には存在しなかった灰色の 班点が観察され，10 回後ではこの班点が連続的になり 直線之なっている。このことから，キャリアレベルの低 下はカー回転角の減少によるものであることがわかっ た，さらに，この灰色部分がトラック中心にあることか ら，キャリアレベルの低下およびノイズレベルの上昇 は, 光スポット中心部における $\mathrm{Pt} / \mathrm{Co}$ 膜の磁気特性の 㸓化に起因しており, 光照射による熱的な損傷が原因で あると考えられる。

\section{2 シミュレーション}

光照射時の熱による磁気特性の少化を検討するため に，ディスクの温度分布を数値シミュレーションを用い て調べた. Table 1 に各層の熱定数を示す ${ }^{8)} . \mathrm{Pt} / \mathrm{Co}$ 膜お よび $\mathrm{Au}$ 膜の熱伝導率は, 電気抵抗率を測定してウィー デマン・フランッの法則9かから求めたＡＡ膜の密度およ び比熱はバルクの文献值 ${ }^{10)}, \mathrm{Pt} / \mathrm{Co}$ 膜のそれは, 文献 值を $\mathrm{Pt}$ と $\mathrm{Co}$ の膜厚比で換算して算出した.

Fig. 6 は, Fig. 3 の実験で用いた $\mathrm{DC}$ 光パワー $P_{\mathrm{E}}$ を 照射した際の磁性膜の定常的な温度を計算したものであ る. $\mathrm{Pt} / \mathrm{Co}$ 膜のピーク温度が低いほど書き換え回数は多 くなっていることから，ピーク温度が高いほじ磁気特性 の少化が大きいことがわかる．このピーク温度は，保護
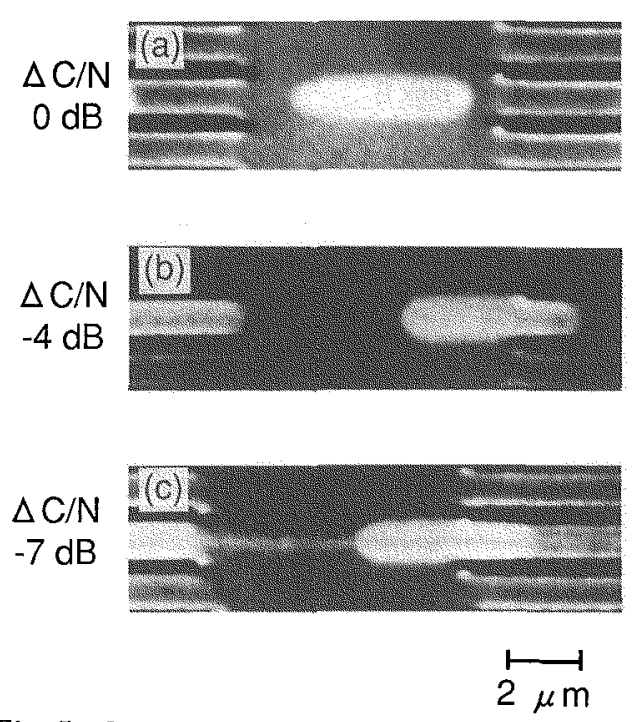

Fig. 5 Observed domains (a) at initial recorded state, (b) after $10^{3}$ cycles and (c) after $10^{4}$ cycles.

Table 1 Thermal parameters used for the calculation.

\begin{tabular}{|c|c|c|c|}
\hline & $\begin{array}{c}\text { density } \\
\left(\mathrm{kg} / \mathrm{m}^{3}\right)\end{array}$ & $\begin{array}{c}\text { specific heat } \\
(\mathrm{J} / \mathrm{kg} \cdot \mathrm{K})\end{array}$ & $\begin{array}{c}\text { heat conductivity } \\
(\mathrm{W} / \mathrm{m} \cdot \mathrm{K})\end{array}$ \\
\hline $\mathrm{Pt} / \mathrm{Co}$ & $18 \times 10^{3}$ & 214.5 & 17 \\
\hline $\mathrm{SiN}$ & $3.2 \times 10^{3}$ & 740 & 10 \\
\hline $\mathrm{Au}$ & $19.32 \times 10^{3}$ & 128 & 248 \\
\hline UV resin & $1.2 \times 10^{3}$ & 1500 & 0.2 \\
\hline air & $0.0013 \times 10^{3}$ & 1000 & 0.03 \\
\hline
\end{tabular}

膜を $\operatorname{SiN}$ 膜（ディスク B) から Au膜（ディスクC）に かえることにより，約 $770^{\circ} \mathrm{C}$ から約 $430^{\circ} \mathrm{C}$ に減少して いる.これは,ディスク Cの保護膜である Auが高い熱 伝導率を有するため熱拡散層としての作用に優れてお り，中心部の熱をすばやく周囲に逃がし膜のピーク温度 を下げる効果が大きいためであると考えられる. 今回の 実験およびシミュレーションでは, 消去磁区幅を 1.2 $\mu \mathrm{m}$ に設定したが， $1 \mu \mathrm{m}$ 以下の狭い磁区幅にした場合, ディスク C が最も高い消去パワーを必要とする (Fig. 2). しかしながら，書き換え特性に影響するピーク温度 は他のディスクより低くなるために，消去磁区幅を変え ても，書き換え特性に枋けるディスクCの優越性は変わ らないと考えられる. 以上から，熱拡散層を設けて Pt/ Co 膜内のピーク温度を下げることにより書き換え回数 は向上することがわかった。

Fig. 6 では，磁区幅を $1.2 \mu \mathrm{m}$ に設定しているにも関 わらず, トラック中心から $\pm 0.6 \mu \mathrm{m}$ 離れた位置での温 


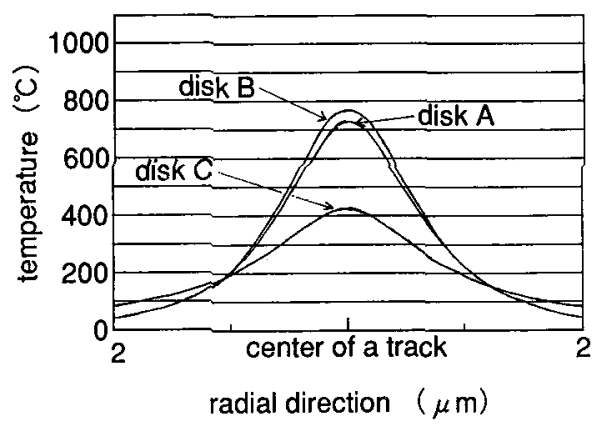

Fig. 6 Calculated temperature distribution in the magnetic layers of three disks for DC laser beam irradiation.

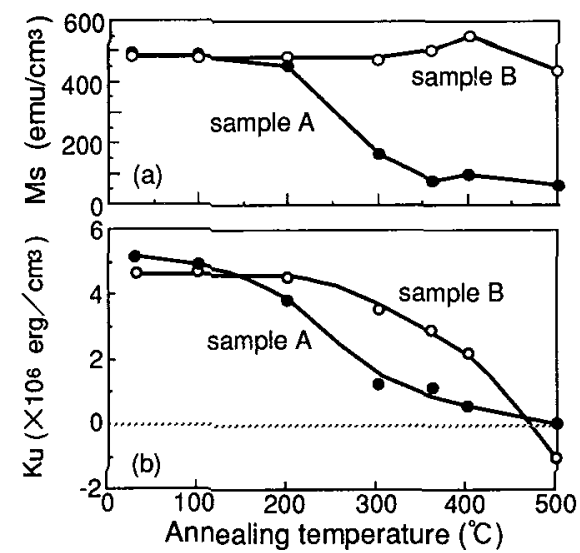

Fig. 7 Annealing temperature dependence of (a) $M_{\mathrm{s}}$ and (b) $K_{\mathrm{u}}$.

度が各ディスクによって異なっている。この原因として は，各ディスクの熱構造が異なるために温度勾配が異な り，その結果，磁区形成における磁壁エネルギーの寄与 が異なるためであると考えられる，この磁壁エネルギー の寄与が，磁壁の位置にどのように影響するかは明らか ではないが, 少なくとす $\mathrm{Pt} / \mathrm{Co}$ 膜での磁壁の位置は温 度のみで決まらないと考えられる。磁区幅李議論する場 合には，今回示したピーク温度のみでなく， $K_{\mathrm{u}}, M_{\mathrm{s}}, H_{\mathrm{c}}$ などを考慮に入れ，磁界計算あるいはエネルギー計算を 行う必要がある。

\section{3 熱処理実験}

書き換え劣化は，レーザ光照射時の温度上密接に関 わっている，そこで，本論文では昇温による磁性膜の劣 化に焦点をしぼり，Pt/Co 膜の熱処理実験を行って書き 換えによる磁性膜の劣化メカニズムについて考察した。 熱好理実験は実際の書き換え時と同様の条件にするため 空気雾囲気中で行った．Si 基板上にディスク $\mathrm{A}, \mathrm{B}, \mathrm{C}$ と 同じ記録膜を積層した 3 種類の $\mathrm{Pt} / \mathrm{Co}$ 膜を 100

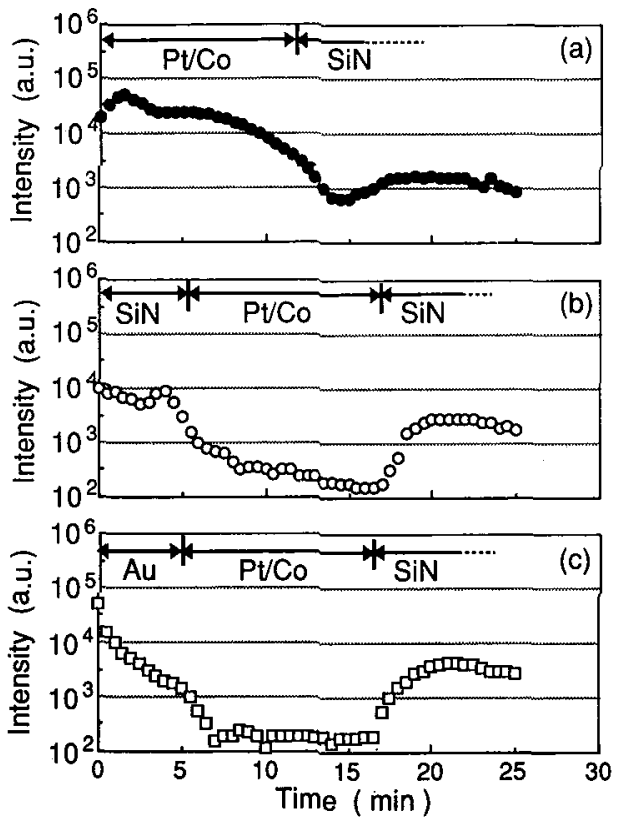

Fig. $8{ }^{18} \mathrm{O}_{2}$ content in $\mathrm{Pt} / \mathrm{Co}$ multilayers of (a) sample A, (b) sample B and (c) sample C. The content was measured by secondary ion mass spectroscopy.

$500^{\circ} \mathrm{C}$ の各温度で 30 分間熱好理した後, 急冷して室温 に戻し磁気特性を測定した，以後，これらの試料をそれ ぞれ試料 A, B, C とする。

試料 A，B を熱処理したときの磁気特性の変化を Fig. 7 に示す。試料 B では $300^{\circ} \mathrm{C}$ 以下で飽和磁化 $\left(M_{\mathrm{s}}\right)$ の変 化は見られず，それ以上の温度で増大している。これは $\mathrm{Pt}$ 層と Co 層界面で合金化が起こり, Pt/Co 膜よりあ $M_{\mathrm{s}}$ の大きな合金層が形成されたためであると考元られ

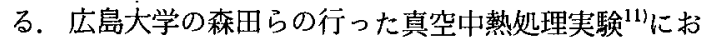
いても $300^{\circ} \mathrm{C}$ 以上の熱処理において $M_{\mathrm{s}}$ が増大するとい う結果を得ている. また, $K_{\mathbf{u}}$ は $200 \sim 300^{\circ} \mathrm{C}$ でわずかに 減少するあのの，400 C においてあ $K_{\mathrm{u}}$ は正，すなわち 垂直磁化膜である. 一方, 試料 A においては $K_{\mathrm{u}}, M_{\mathrm{s}}$ と あに $200^{\circ} \mathrm{C}$ 以上で著しく減少し, 保護膜の有無によって 熱安定性が異なることがわかる。

Fig. 8 は $300^{\circ} \mathrm{C}$ 熱処理後の記録膜中の ${ }^{18} \mathrm{O}_{2}$ に対する SIMS 分析結果である. 横軸は記録膜の膜厚方向に対応 しており，図中の矢印は記録膜の積層構造を示してい る. Fig. 8 からわかるように, 試料 $\mathrm{A} の \mathrm{Pt} / \mathrm{Co}$ 膜中に は, 試料 $\mathrm{B}, \mathrm{C}$ と比べ約 2 桁多い ${ }^{18} \mathrm{O}_{2}$ が検出された。 こ の結果より, 保護膜のない $\mathrm{Pt} / \mathrm{Co}$ 膜の熱安定性が保護 膜を設けた場合より劣る原因は, Pt/Co 膜が酸化される

日本応用磁気学会誌 Vol. 17, No. 5, 1993 

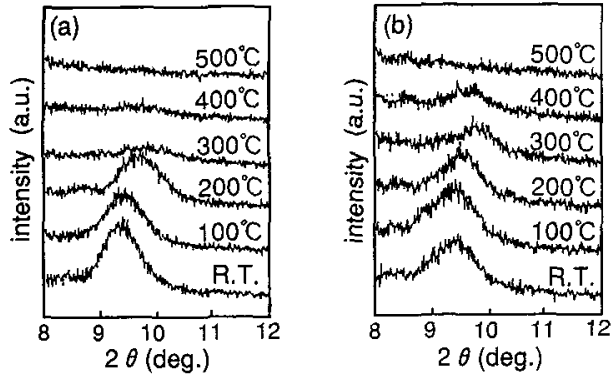

Fig. 9 X-ray diffraction patterns of annealed $\mathrm{Pt} / \mathrm{Co}$ multilayers for (a) sample $\mathrm{A}$ and (b) sample B.

ためであることがわかった。したがって，試料 A での熱 処理による $M_{\mathrm{s}}$ の急激な減少は，Co が部分的に磁化を 失っているためであり，また，試料 $\mathrm{A} の K_{\mathrm{u}}$ が試料 $\mathrm{B} に$ 比べて早期に少化することも酸化が関与しているためと 推察される.

Fig. 9 には，熱処理後の試料 A, B における $\mathrm{Pt} / \mathrm{Co}$ 膜 の小角 X 線回折パターンを示した。いずれの構造にお いても，熱処理温度を高くすることによって多層構造に 起因する回折ピーク強度は減少し, $500^{\circ} \mathrm{C}$ 熱処理後では ピークは消滅している．このことから，熱処理によって $\mathrm{Pt}$ 層と Co 層界面で Pt 原子と Co 原子の相互拡散（合 金化）が起こり，温度が高いほど合金化が促進されるこ とが確認された．ただし，ピーク強度の減少傾向に違い が見られ，試料 B では $400^{\circ} \mathrm{C}$ 熱処理後においても回折 ピークが認められるのに対して, 試料 A では熱処理温 度 $300^{\circ} \mathrm{C}$ でピーク強度がかなり減少している.したがっ て, 試料 Aでは酸化む多層構造を乱す要因になってい ると考元られる。

以上より，Pt/Co 膜における書き換元劣化の原因は次 のように考察される. $\mathrm{DC}$ 光照射により $\mathrm{Pt} / \mathrm{Co}$ 膜の温度 が上昇し，Pt 層と Co 層界面で合金化が起こる，保護膜 のない 2 層構造ディスクの場合には Co の酸化も一因と なって， $K_{\mathrm{u}}$ が娍少し面内磁化成分が增大する。 ただし， Fig. 3 からわかるように，書き換え回数が保護膜の有無 ではなく $\mathrm{Pt} / \mathrm{Co}$ 膜のピーク温度に依存していることか ら，劣化に対する酸化の影響は合金化に比べて小さい， この步化が進むとヒステリシスループの角形比は 1 末 満になり0磁界における残留力一回転角が減少し，その 結果キャリアレベルが低下してノイズレベルが上昇す る. Pt 層と Co 層界面での合金化は高温ほど起こりやす いので，熱拡散層を設けてピーク温度を下げることによ り，書き換え劣化は改善される，また，酸化保保護膜を 設けることにより防ぐことができる。
本研究では，書き換えによる $\mathrm{C} / \mathrm{N}$ の劣化現象を, $\mathrm{Pt} /$ Co 膜の磁気特性の熱による劣化に焦点をしぼり考察し たが，藤本らは UV 樹脂が熱により劣化していることを 報告しておる ${ }^{122}$, 著者らすUV 樹脂が变形していること を確認している，書き換え劣化か磁気特性，UV 樹脂い ずれの劣化によるあのかは現時点では不明である，劣化 過程をさらに詳細に調べることにより明らかになると考 えられる。

\section{4. まとめ}

Co-rich の Pt/Co ディスクの書き換え特性を調べ，書 き換え回数を制限する原因を究明した。書き換えによる $\mathrm{Pt} / \mathrm{Co}$ 膜の劣化の主な原因は，レーザ光の熱により $\mathrm{Pt}$ 層とCo 層の界面で Pt 原子よCo 原子の相互拡散が起こ り垂直磁気異方性エネルギーが隇少するためであると考 えられる。ささらに，2 層構造ディスクの場合には $\mathrm{Pt} / \mathrm{Co}$ 膜の酸化が起こっていると推測される，したがって，高 いキュリー温度を有する $\mathrm{Pt} / \mathrm{Co}$ ディスクにおいても， 熱拡散層を設けて記録膜のピーク温度を下げることに よって，また，保護膜を設けCo の酸化を防止すること によって書き換え回数が向上する，本研究では $1.2 \mu \mathrm{m}$ 幅の磁区を記録できる DC 光を連続照射した場合，保護 膜を SiN 層としたディスクの書き換元回数が $10^{2}$ 回で あるのに対し，Au 層を設けたディスクにおいて $10^{5}$ 回 の書き換え回数を達成した。

\section{文献}

1) S. Hashimoto, Y. Ochiai and K. Aso: J. Appl. Phys., 67, $2136(1990)$.

2) P. F. Carcia: Appl. Phys. Lett., 56, 2345 (1990).

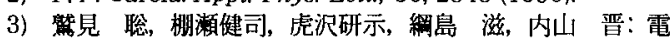
子情報通信学会磁気記録研究会資料, MR 89-45 (1990).

4）中村純子，粟野博之，高橋正彦，尾島正哲：第15 回日本 応用磁気学会学術講演概要集, p. 305 (1991).

5）続山浩二，重松茂人，渡辺 淳，戸上蜼司：日本応用磁気 学会誌, 16, 117 (1992).

6) P. F. Carcia, W. B. Zeper, H. W. van Kesteren, B. A. J. Jacobs and J. H. M. Spruit: Proc. of MORIS '91, J. Mag. Soc. Japan., 15 (Suppl. No. S1), 151 (1991).

7) J. Nakamura: unpublished data.

8) 高橋正彦: 日本応用磁気学会誌，13,603 (1989).

9）例えば，キッテル：第 5 版固体物理学入門 上， p. 165 (丸善, 東京, 1976)。

10）例元议，飯田 等編：物理定数表（朝倉書店，東京， 1979).

11）森田 昇，縄手雅彦，本多茂男：日本応用磁気学会誌，16, 325 (1992).

12) 藤本健介, 前坂明弘, 橋本俊一：第 16 回日本㐫用磁気学 会学術講演概要集, p. 431 (1992).

1993 年 5 月 6 日受理, 1993 年 7 月 7 日採録 